\title{
Synthesis of partial glycerides rich in a-linolenic acid efficiently from silkworm pupa oil with immobilized lipase MAS1-H108A
}

\author{
Haipeng YUE (D), Ri Ming $\mathrm{LUO}^{2}$, Xiaoli QIN³, Shi HE${ }^{1}$, Bo YANG ${ }^{4}$, Sentai LIAO ${ }^{5}$, Weifei WANG5*, \\ Yonghua WANG ${ }^{1 *}$
}

\begin{abstract}
In this paper the ability of immobilized lipase MAS1-H108A to prepare $\alpha$-linolenic acid-rich partial glycerides was studied. The effects of different reaction conditions on the yield of Diacylglycerol (DAG) and Monoglyceride (MAG) were investigated, including substrate molar ratio, substrate concentration, temperature and lipase dosage. The highest yield (63.92\% of MAG and $30.61 \%$ of DAG) was obtained when silkworm pupa oil/glycerol ratio of $1: 3$, lipase dosage was $50 \mathrm{U} / \mathrm{g}$, substrate concentration was $40 \%(\mathrm{w} / \mathrm{v})$, at $40{ }^{\circ} \mathrm{C}$. Under the optimal conditions, the scale-up (50 times) and single-stage molecular distillation were carried out to separate DAG and MAG, the yield of MAG in the light phase was $99.18 \%$, and the concentration of DAG in the heavy phase was $89.47 \%$, $\alpha$-linolenic acid in MAG and DAG accounted for $28.96 \%$ and $28.23 \%$, respectively. The results can be shown that the immobilized lipase MAS1-H108A has excellent potential for enzymatic glycerolysis to prepare functional partial glycerides.
\end{abstract}

Keywords: lipase; glycerolysis; partial glycerides; silkworm pupa oil.

Practical application: Silkworm pupa oil contains the highest oil content of the $\alpha$-linolenic acid in the animal oil , the application prospect is extremely wide, and it is also possible to use the immobilized lipase MAS1-H108A for enzymatic glycerolysis to prepare functional partial glycerides with a high content $\alpha$-linolenic acid. At the same time, the results of the scale-up reaction are also very satisfactory. Therefore, this experiment has high application value in the enzymatic industrial production of functional partial glycerides.

\section{Introduction}

Lipase can catalyze various reactions, such as hydrolysis, esterification, transesterification, acidolysis, alcoholysis and aminolysis, and has good biological properties (Li et al., 2016). Due to its excellent catalytic performance, including regioselectivity, enantioselectivity and stereoselectivity, as well as high specificity and activity under mild reaction conditions, it has been applied to various industries (Rodrigues et al., 2013). Partial glyceride lipase has become a research hotspot because it can be used to efficiently prepare partial glycerides (DAG and MAG) and remove partial glycerides from glyceride mixtures (Singh \& Mukhopadhyay, 2014; Bavaro et al., 2020). However, the types of partial glyceride lipase are extremely rare. Therefore, it is of great significance to develop an alternative partial glyceride lipase.

At present, partial glycerides were prepared by enzymatic glycerolysis in solvent-free systems, organic solvent systems, supercritical $\mathrm{CO}_{2}$ systems and the addition of surfactants. However, the effects of most reactions are not satisfactory. Li Yue et al. (Li et al., 2018) used Candida antarctica lipase B to catalyze the glycerolysis of soybean oil for $24 \mathrm{~h}$ in a solvent-free system, the yields of DAG and MAG were $64.28 \%$ and $20.15 \%$, respectively. But the shortcomings of the solvent-free system were also obvious, the mass transfer effect between glycerin and glyceride was very poor. Wang Weifei et al. (Wang et al., 2011) used Novozym 435 to enzymatically glycerolize soybean oil in a tert-butanol system to prepare DAG, the conversion rate of soybean oil and the yield of DAG reached $98.7 \%$ and $48.5 \%$ at $24 \mathrm{~h}$, respectively. Although the final reaction yield has increased, the reaction time was too long. Valério et al. (2010) explored the use of immobilized lipase (Novozym 435) and the surfactant (Tween 65) to produce MAG and DAG from emulsified the two reactants into reverse micelles (glycerol-in-oil) before using Lipozyme 435 enzymatic glycerolization of fish oil to improve the process efficiency of the SC- $\mathrm{CO}_{2}$ medium and the mass transfer of glycerol/oil in the three-phase system, and produced about 75\% of MAG and DAG within $1 \mathrm{~h}$. It was not difficult to see that the types and reaction efficiency of lipases available in the process of preparing partial glycerides by enzymatic glycerolysis were two major problems. In addition, in many literature reports on enzymatic glycerolysis, the most commonly used immobilized lipase was Novozym 435. The reason was that there were very few lipases that were suitable for catalyzing the reaction of alcohols and esters. Lipase MAS1 was a newly developed biocatalyst with

${ }^{1}$ School of Food Science and Engineering, South China University of Technology, Guangzhou, P. R., China

${ }^{2}$ Guangdong Yue-shan Special Nutrition Technology Co., Ltd., Foshan, China

${ }^{3}$ School of Food Science and Engineering, Southwest University, Beibei, Chongqing. P. R., China

${ }^{4}$ School of Bioscience and Bioengineering, South China University of Technology, Guangzhou, P. R., China

${ }^{5}$ Sericultural and Agri-Food Research Institute, Guangdong Academy of Agricultural Sciences, Guangzhou, P. R., China

*Corresponding author: wangweifei@gdaas.cn, yonghw@scut.edu.cn 
excellent catalytic properties in recent years. It has been proved to have excellent esterification ability, but there was no report about its catalytic ability in glycerolysis reaction.

In the process of studying the activation mechanism of lipase MAS1, our laboratory discovered a mutant lipase (MAS1H108A) with an enzyme activity of $500 \mathrm{U} / \mathrm{g}$. In order to evaluate the potential ability of MAS1-H108A to catalyze glycerolysis reaction to prepare $\alpha$-linolenic acid-rich partial glycerides, three commercial immobilized lipases (Novozym 435, Lipozyme TLIM and Lipozyme RMIM) and MAS1-H108A were compared, and the effects of substrate molar ratio, substrate concentration, temperature and lipase dosage on the glycerolysis reaction were investigated when MAS1-H108A was used as a catalyst. At the same time, after scale-up reaction and molecular distillation purification, the yield change of partial glycerides with time and the influence of glycerolysis on the fatty acid composition in oil were discussed, and finally satisfactory results were obtained.

\section{Experiments}

\subsection{Materials}

The pPICZaA-MAS1-X33 expression strain was stored at $-80^{\circ} \mathrm{C}$ in our laboratory. Novozym 435、Lipozyme TLIM and Lipozyme RMIM were obtained from Novo Nordisk (Den-Mark). Silkworm pupa oil (TAG > 98\%) was provided by the Institute of Sericulture and Agricultural Product Processing, Guangdong Academy of Agricultural Sciences. Hexane, 2-propanol, and formic acid (all chromatographic grades) were purchased from Kermel Chemical Reagent Co, Ltd. (Tianjin,China). Methanolic boron trifluoride solution (15\% BF3) and standards of monooleoylglycerol, dioleoylglycerol (15\% of 1,2-dioleoylglycerol and $85 \%$ of 1,3-dioleoylglycerol), and 37-component fatty acid methyl esters (FAME) mix $\left(\mathrm{C}_{4}-\mathrm{C}_{24}\right)$ were sourced from SigmaAldrich. Other chemicals are of analytical grade.

\subsection{Glycerolysis of silkworm pupa oil by immobilized lipase MAS1-H108A}

Four immobilized lipases were selected to catalyze the glycerolysis of silkworm pupa oil to prepare partial glycerides. The effects of the substrate concentration (20\% (w/v), 30\% (w/v), 40\% $(\mathrm{w} / \mathrm{v}), 50 \%(\mathrm{w} / \mathrm{v})$ and $60 \%(\mathrm{w} / \mathrm{v}))$, the silkworm pupa oil:glycerol ratio $(1: 1,1: 2,1: 3,1: 4,1: 5)$, reaction temperature $\left(30^{\circ} \mathrm{C}, 40^{\circ} \mathrm{C}\right.$, $50^{\circ} \mathrm{C}$ and $\left.60^{\circ} \mathrm{C}\right)$ and lipase dosages $(25 \mathrm{U} / \mathrm{g}, 50 \mathrm{U} / \mathrm{g}, 75 \mathrm{U} / \mathrm{g}$, $100 \mathrm{U} / \mathrm{g}$ and $125 \mathrm{U} / \mathrm{g}$ ) were investigated, respectively. Samples were collected periodically (per $2 \mathrm{~h}$ ) till $8 \mathrm{~h}$ of reaction and were analyzed by high-performance liquid chromatography (HPLC).

The yield of each component was expressed as the percentage of the peak area determined by HPLC, and the calculation methods were as (1),(2),(3) and (4):

$$
\begin{aligned}
& \text { MAG yield }(\%)=\frac{\text { MAG }(\%)}{\mathrm{MAG}(\%)+\mathrm{DAG}(\%)+\mathrm{TAG}(\%)} \times 100 \\
& D A G \text { yield }(\%)=\frac{\mathrm{DAG}(\%)}{\mathrm{MAG}(\%)+\mathrm{DAG}(\%)+\mathrm{TAG}(\%)} \times 100
\end{aligned}
$$

TAG yield $(\%)=\frac{\mathrm{TAG}(\%)}{\mathrm{MAG}(\%)+\mathrm{DAG}(\%)+\mathrm{TAG}(\%)} \times 100$

The method for calculating the conversion rate of TAG was as follows:

$T A G$ conversion rate $(\%)=\frac{\mathrm{X}_{2}-\mathrm{X}_{1}}{X_{2}} \times 100$

X1- - The yield of TAG in the product;

$\mathrm{X} 2$ - - The yield of TAG in raw materials.

\subsection{Scale-up reaction}

A scale-up experiment (50 times) for the preparation of partial glycerides from glycerolized silkworm pupa oil was carried out to verify its application prospects in production. Under optimized single factor conditions, the substrate mass was expanded to $500 \mathrm{~g}$. The container with the substrate was placed in a magnetic constant temperature water bath stirring pot with a stirring rate of $150 \mathrm{rpm} / \mathrm{min}$, and HPLC was used to determine the components of the reaction system regularly.

\subsection{Separation of DAG and MAG by single-stage molecular distillation}

The organic solvent (tert-butanol) in the reaction system was evaporated and recovered by a rotary evaporator under vacuum. After obtaining the upper oil sample, it was separated by singlestage molecular distillation (produced by VTA, Germany) to purify DAG and MAG in grease, the distillation pressure was $1 \mathrm{~Pa}$, the distillation temperature was $180^{\circ} \mathrm{C}$, the speed of the scraper was $400 \mathrm{rpm} / \mathrm{min}$, and the feed rate was $2 \mathrm{~mL} / \mathrm{min}$.

\subsection{Analysis of the composition of the reaction mixture by HPLC}

The analysis of the composition of the reaction mixtures was carried out using a normal-phase HPLC equipped with a refractive index detector and a Phenomenex Luna column (250 $\mathrm{mm} \times 4.6 \mathrm{~mm}$ i.d., $5 \mu \mathrm{m}$ particle size) according to the method previously described by Li et al. (2015). with a minor modification. The mobile phase consisted of n-hexane, isopropanol and formic acid (21:1:0.003, by vol) with a flow rate of $1 \mathrm{~mL} / \mathrm{min}$. Peaks in HPLC were evaluated by comparison of their retention times with those known standards.

In this study, the yield of each component was expressed as the percentage of the peak area determined by HPLC, and the calculation methods were as II-B.

\subsection{Determination of fatty acid composition in silkworm pupa oil and reaction products by GC}

The silkworm pupa oil and reaction products were initially methylated to Fatty Acid Methyl Ester (FAME) according to the method described by Wang et al. (2010). Then, FA composition of the final FAME product was determined using GC (Agilent 7890A) equipped with a capillary column CP-Sil $88(60 \mathrm{~mm} \times 0.25 \mathrm{~mm}$, 
$0.2 \mu \mathrm{m})$. The detailed analysis was carried out according to the method described by Qin et al. (2011).

\subsection{Statistical analysis}

All experiments were carried in triplicate. The results were presented as the means \pm standard deviations (SD). The statistical significance of differences was measured by a one-way analysis of variance (ANOVA).

\section{Results and discussion}

\subsection{Comparison of four immobilized lipases on the glycerolysis}

Lipozyme RMIM, Immobilized lipase MAS1-H108A, Lipozyme TLIM, and Novozym 435, were used to the preparation of partial glycerides, under the reaction conditions of the substrate molar ratio of silkworm pupa oil to glycerol was 1:3, the substrate concentration (tert-butanol as organic solvent) was $40 \%(\mathrm{w} / \mathrm{v})$, lipase dosage was $50 \mathrm{U} / \mathrm{g}$ (Lauric acid esterification activity is $500 \mathrm{U} / \mathrm{g}$ ), and at $40^{\circ} \mathrm{C}$ for $6 \mathrm{~h}$. Table 1 compares the ability of the four immobilized lipases to catalyze the glycerolysis of silkworm pupa oil and glycerol to produce partial glycerides. It could be seen that the TAG conversion efficiency of MAS1-H108A was the highest, which reached $94.53 \%$. The TAG conversion efficiency of Novozym 435, Lipozyme TLIM, Lipozyme RMIM were 85.92\%, $36.29 \%, 32.84 \%$, respectively. Moreover, immobilized lipase MAS1-H108A showed similar resistance to organic solvents as Novozym 435 (Dalla Rosa et al., 2009), the enzyme activity of them will be reduced in the tert-butanol system. However, in this study, the catalytic performance was better than that of Novozym 435. This might because the immobilized lipase MAS1H108A has stronger non-position selectivity than Novozym 435 (Wang et al., 2017), which will strengthen catalyze acyl transfer. Therefore, immobilized lipase MAS1-H108A was selected as the catalyst in the subsequent experiments.

The reaction mixture that was used in the reaction system, was stirred at $40^{\circ} \mathrm{C}$, included $10 \mathrm{~g}$ of glycerol and silkworm pupa oil (3:1 M ratio), $25 \mathrm{~mL}$ tert-butyl alcohol and $1 \mathrm{~g}$ of lipase .

\subsection{Glycerolysis of silkworm pupa oil by immobilized lipase MAS1-H108A}

Effect of different substrate molar ratios on the glycerolysis

The effect of substrates molar ratio on the glycerolysis of silkworm pupa oil catalyzed by immobilized lipase MAS1-H108A is shown in Figure 1. When the molar ratio of silkworm pupa oil and glycerol was increased from 1:1 to 1:3, the yield of partial glycerides was increased significantly. And the highest yield (95\%) of partial glycerides was obtained when the silkworm pupa oil:glycerol ratio reached to 1:3. This might be due to insufficient glycerol addition made the reaction reach the equilibrium point in advance, which resulted many residual silkworm pupa oil. When increased silkworm pupa oil:glycerol ratio to $1: 4$ and 1:5, the yield of partial glycerides were less than that of silkworm pupa oil:glycerol ratio of 1:3. The reason maybe as the glycerol yield increases, the mass transfer of the system will become difficult (Krüger et al., 2010). Thus, the silkworm pupa oil:glycerol ratio of $1: 3$ was selected as the reaction condition in the subsequent research.

\section{Effect of different substrate concentrations on the glycerolysis}

Tert-butanol can be used as a reaction solvent to improve the miscibility of the substrate, enhance the mass transfer function, and increase the reaction rate and the reaction efficiency (Zeng et al., 2010).The effect of substrate concentration on the glycerolysis of silkworm pupa oil catalyzed by immobilized lipase MAS1-H108A is shown in Figure 2. It could be clearly seen that yield of partial glycerides with a substrate concentration of $20 \%(\mathrm{w} / \mathrm{v})$ was the lowest. It indicated that a larger substrate concentration was beneficial to the reaction. When the substrate

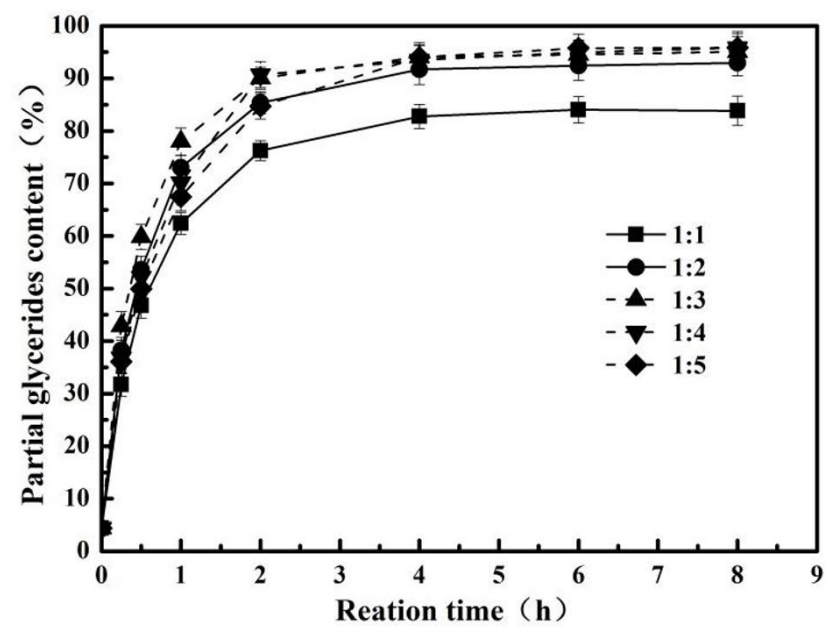

Figure 1. Effect of substrate molar ratio on silkworm pupa oil catalyzed by immobilized lipase MAS1-H108A.

Table 1. Preparation of partrial glycerides by glycerolysis of silkworm pupa oil by four different immolibilized lipases.

\begin{tabular}{|c|c|c|c|c|c|c|c|c|c|c|c|c|}
\hline \multirow{3}{*}{$\begin{array}{l}\text { Time } \\
\text { (h) }\end{array}$} & \multicolumn{12}{|c|}{ Immobilized Lipase } \\
\hline & \multicolumn{3}{|c|}{ Lipozyme RMIM } & \multicolumn{3}{|c|}{ Immobilized MAS1-H108A } & \multicolumn{3}{|c|}{ Lipozyme TLIM } & \multicolumn{3}{|c|}{ Novozym 435} \\
\hline & $\begin{array}{c}\text { TAG } \\
\text { conversion } \\
(\%)\end{array}$ & $\begin{array}{c}\text { DAG } \\
\text { yield(\%) }\end{array}$ & $\begin{array}{c}\text { MAG } \\
\text { yield(\%) }\end{array}$ & $\begin{array}{c}\text { TAG } \\
\text { conversion } \\
(\%)\end{array}$ & $\begin{array}{c}\text { DAG } \\
\text { yield(\%) }\end{array}$ & $\begin{array}{c}\text { MAG } \\
\text { yield(\%) }\end{array}$ & $\begin{array}{c}\text { TAG } \\
\text { conversion } \\
(\%)\end{array}$ & $\begin{array}{c}\text { DAG } \\
\text { yield(\%) }\end{array}$ & $\begin{array}{c}\text { MAG } \\
\text { yield(\%) }\end{array}$ & $\begin{array}{c}\text { TAG } \\
\text { conversion } \\
(\%)\end{array}$ & $\begin{array}{c}\text { DAG } \\
\text { yield(\%) }\end{array}$ & $\begin{array}{c}\text { MAG } \\
\text { yield(\%) }\end{array}$ \\
\hline 0 & 0 & 0 & 0 & 0 & 0 & 0 & 0 & 0 & 0 & 0 & 0 & 0 \\
\hline 1 & $14.65 \pm 0.26$ & $8.16 \pm 0.28$ & $6.49 \pm 0.17$ & $77.99 \pm 0.33$ & $25.09 \pm 0.19$ & $52.90 \pm 0.24$ & $15.69 \pm 1.26$ & $8.64 \pm 0.89$ & $6.69 \pm 1.12$ & $58.36 \pm 2.14$ & $30.62 \pm 1.35$ & $27.94 \pm 0.69$ \\
\hline 2 & $20.51 \pm 0.48$ & $10.04 \pm 0.42$ & $10.47 \pm 0.35$ & $90.06 \pm 0.41$ & $28.26 \pm 0.54$ & $61.80 \pm 0.61$ & $23.37 \pm 2.13$ & $12.11 \pm 1.64$ & $11.23 \pm 1.55$ & $69.67 \pm 1.26$ & $35.42 \pm 0.62$ & $34.78 \pm 0.78$ \\
\hline 4 & $27.15 \pm 0.37$ & $12.88 \pm 0.51$ & $14.27 \pm 0.26$ & $94.07 \pm 0.29$ & $29.64 \pm 0.48$ & $64.43 \pm 0.37$ & $28.9 \pm 0.89$ & $13.56 \pm 2.06$ & $14.38 \pm 2.14$ & $77.14 \pm 0.36$ & $32.64 \pm 2.61$ & $54.26 \pm 1.45$ \\
\hline 6 & $32.84 \pm 0.56$ & $15.03 \pm 0.44$ & $17.45 \pm 0.31$ & $94.53 \pm 0.35$ & $30.61 \pm 0.43$ & $63.92 \pm 0.47$ & $36.29 \pm 1.26$ & $16.32 \pm 0.69$ & $18.81 \pm 0.39$ & $85.92 \pm 1.87$ & $26.63 \pm 1.69$ & $58.92 \pm 1.82$ \\
\hline
\end{tabular}


concentration was boosted to $40 \%$ (w/v), $95.54 \%$ of the glyceride yield was reached and the system was most stable and clearest. The partial glyceride yield of 50\% (w/v) and 60\% (w/v) of the substrate concentration showed no significantly differences and were lower than that of substrate concentration of $40 \%(\mathrm{w} / \mathrm{v})$. Therefore, in the subsequent study, a substrate concentration of $40 \%(\mathrm{w} / \mathrm{v})$ was selected as the reaction condition.

\section{Effect of different temperature on the glycerolysis}

Figure 3 shows the effect of temperature on the glycerolysis of silkworm pupa oil catalyzed by immobilized lipase MAS1H108A. Wang has shown that as the increase of the temperature will lead an improvement of the conversion rate and conversion efficiency of the substrates (Wang et al., 2011). Obviously, when the temperature was $30^{\circ} \mathrm{C}$, the initial reaction rate was low, and the yield of partial glycerides was only $92.34 \%$ till the reaction time reached $8 \mathrm{~h}$. This might be at a low temperature, the mass transfer between the substrates became slower, which has a negative

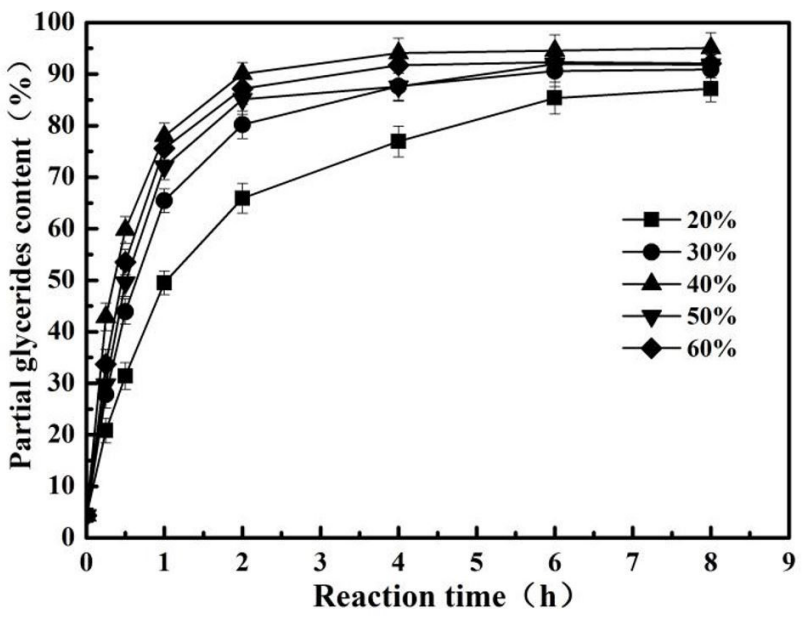

Figure 2. Effect of substrate concentration on silkworm pupa oil catalyzed by immobilized lipase MAS1-H108A.

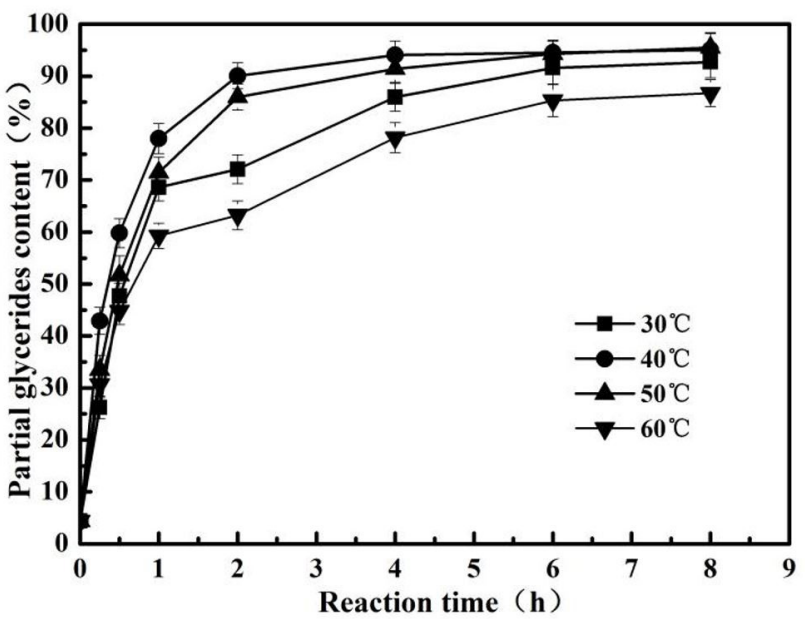

Figure 3. Effect of temperature on silkworm pupa oil catalyzed by immobilized lipase MAS1-H108A effect on the reaction. The highest yield of the reaction products can be obtaind when the temperature was $40^{\circ} \mathrm{C}$. However, when increased the reaction temperature beyond $40^{\circ} \mathrm{C}$, the reaction rate was decreased, due to a high temperature will reduce the enzyme activity. Therefore, in the subsequent glycerolysis reaction study, a temperature of $40^{\circ} \mathrm{C}$ was selected as the reaction condition.

\section{Effect of different lipase dosages on the glycerolysis}

The effect of lipase dosage on the glycerolysis of silkworm pupa oil catalyzed by immobilized lipase MAS1-H108A is illustrated in Figure 4. When the lipase dosage was $50 \mathrm{U} / \mathrm{g}$, the partial glycerides yield in $4 \mathrm{~h}$ was $95.06 \%$ (including the yield of DAG was $29.83 \%$ and the MAG was $65.23 \%$ ). The continuous increase of lipase dosage had no obvious effect on the accumulation of partial glycerides. We guessed that the lipase dosage and substrates were saturated with each other or the lipase dosage was so much, that hindered the mass transfer (Zha et al., 2014). Thus, $50 \mathrm{U} / \mathrm{g}$ as the optimal lipase dosage was selected.

\subsection{Scale-up reaction}

Exploring the scale-up experiment of the immobilized lipase MAS1-H108A catalyzing the preparation of partial glycerides with changes in time, under the conditions that the substrate concentration was $40 \%(\mathrm{w} / \mathrm{v})$, the molar ratio of silkworm pupa oil and glycerol was $1: 3$, the reaction temperature was $40{ }^{\circ} \mathrm{C}$, the lipase dosage was $50 \mathrm{U} / \mathrm{g}$, and the relationship between partial glycerides and reaction time was discussed. As shown in Figure 5, when the reaction progressed to $6 \mathrm{~h}$, the conversion rate of TAG in silkworm pupa oil reached $96.98 \%$, and the yields of DAG and MAG were basically stable, $30.16 \%$ and $66.35 \%$, respectively. Valério et al. (2009) explored the use of immobilized lipase (Novozym 435) and the surfactant (aerosol-OT or AOT) to produce MAG and DAG from olive oil in a pressurized n-butane solvent medium, 81.3\% (71.9\% MAG and $9.4 \%$ DAG) partial glycerides was obtained. Obviously, in current study, immobilized lipase MAS1-H108A have a better

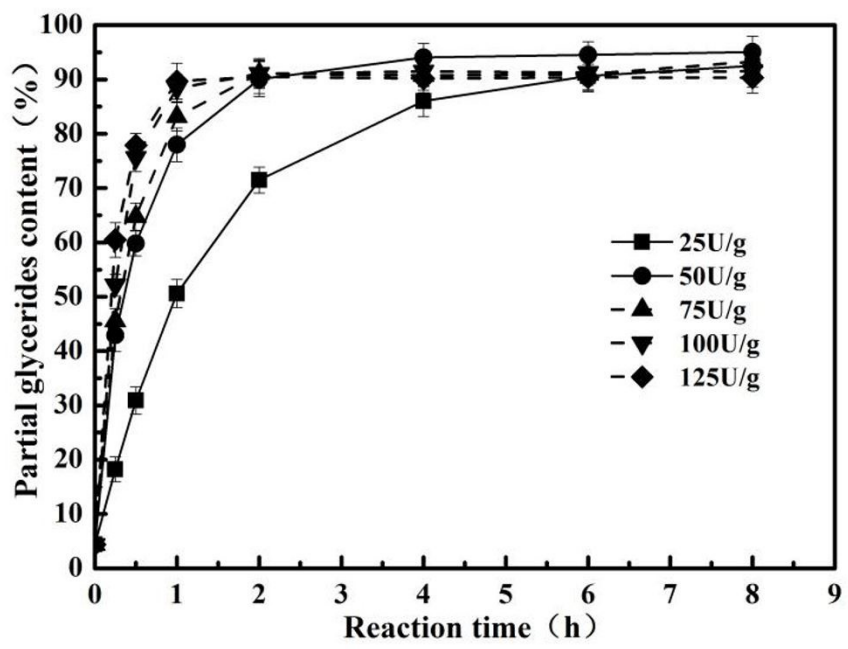

Figure 4. Effect of lipase dosage on silkworm pupa oil catalyzed by immobilized lipase MAS1-H108A. 
Table 2. Acyl yield in silkworm pupa oil and products.

\begin{tabular}{lccc}
\hline & TAG yield (\%) & DAG yield (\%) & MAG yield (\%) \\
\hline Products of scale-up & 3.49 & 30.16 & 66.35 \\
Distillation light phase & 0.52 & 0.30 & 99.18 \\
Distillation heavy phase & 9.53 & 89.47 & ND \\
\hline
\end{tabular}

Table 3. Fatty acid composition in silkworm pupa oil and products.

\begin{tabular}{|c|c|c|c|c|c|c|c|c|}
\hline \multicolumn{9}{|c|}{ Types of fatty acids } \\
\hline Yield & $\mathrm{C} 16: 0(\%)$ & $\mathrm{C} 16: 1(\%)$ & C18:0 (\%) & C18:1 (\%) & C18:2 (\%) & C18:3 (\%) & Others (\%) & $\begin{array}{c}\text { UFA(\%) } \\
\text { (unsaturated } \\
\text { fatty acid) }\end{array}$ \\
\hline Silkworm pupa oil & 21.76 & 2.97 & 3.83 & 32.17 & 6.42 & 29.76 & 4.45 & 71.32 \\
\hline$(\mathrm{DAG}+\mathrm{MAG})$ & 20.94 & 3.02 & 3.86 & 32.05 & 6.29 & 29.84 & 4.29 & 71.2 \\
\hline
\end{tabular}

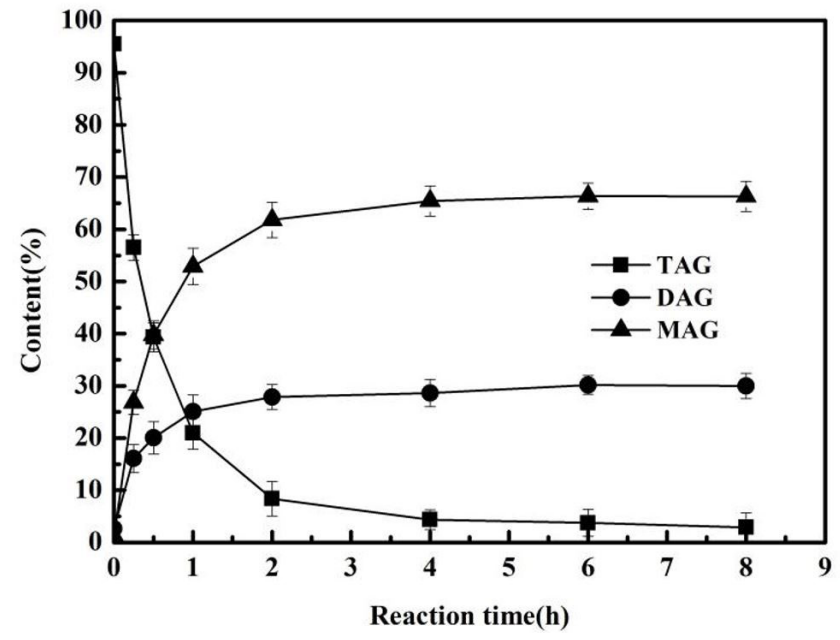

Figure 5. The effect of time on the yield of diglycerides and monoglycerides.

performance in preparing partial glycerides. This was due to the immobilized lipase MAS1-H108A has stronger non-positional selectivity than Novozym 435 , which has a positive effect on more DAG turning into MAG.

\subsection{Separation and fatty acid composition of DAG and MAG}

In order to purify the final product, molecular distillation equipment was used to purify the final product and separate DAG and MAG. Table 2 shows that, after purification by singlestage molecular distillation, MAG and DAG were separated and achieved the concentration of $99.18 \%$ and $89.47 \%$ in their respective phase.

It could be seen from Table 3 that the concentration of a-linolenic acid in raw silkworm pupa oil was $29.76 \%$, and didn't change significantly after glycerolysis reaction. Moreover, it also showed that the enzymatic glycerolysis reaction had no significant influence on the other fatty acid compositions, which was similar with the report of $\mathrm{Hu}$ et al. (2017).

The reaction mixture that was used in the reaction system, was stirred at $40{ }^{\circ} \mathrm{C}$, included $500 \mathrm{~g}$ of glycerol and silkworm pupa oil (3:1 M ratio), $1.25 \mathrm{~L}$ tert-butyl alcohol and $50 \mathrm{~g}$ of lipase. TAG triacylglycerols,MAG monoacylglycerols, DAG diacylglycerols. The reaction mixture that was used in the reaction system, was stirred at $40^{\circ} \mathrm{C}$, included $10 \mathrm{~g}$ of glycerol and silkworm pupa oil (3:1 M ratio), $25 \mathrm{~mL}$ tert-butyl alcohol and $1 \mathrm{~g}$ of lipase. MAG monoacylglycerols, DAG diacylglycerols, UFA unsaturated fatty acid

\section{Conclusions}

Here, we successfully demonstrated the ability of immobilized lipase MAS1-H108A to prepare the partial glycerides rich in a-linolenic acid. Comparing with three commercial immobilized lipases, immobilized lipase MAS1-H108A was more capable. Under the optimal conditions, the conversion rate of TAG can reach $97.21 \%$ in a short time $(6 \mathrm{~h})$, the yield of DAG in the mixture was $30.61 \%$, and the MAG was $63.92 \%$. In addition, the results of the scale-up reaction were in line with expectations, and the yield of partial glycerides can reach $96.51 \%$ within 6 h. After molecular distillation,the concentration of MAG in the light phase was $99.18 \%$ and in the heavy phase the yield of DAG was $89.47 \%$. These results further indicated that the immobilized lipase MAS1-H108A has great potential in catalyzing the glycerolysis reaction.

\section{Conflict of interest}

The authors declare no conflict of interest.

\section{Author contributions}

Haipeng Yue: Conceptualization, Data curation, Formal analysis, Methodology, Software, Writing-original draft. RiMing Luo: Formal analysis, Investigation. Xiaoli Qin: Resources. Shi He: Writing - Review \& Editing. Bo Yang: Supervision. Sentai Liao:Validation. Weifei Wang: Funding acquisition. Yonghua Wang: Funding acquisition, Project administration. All authors read and approved the final manuscript.

\section{Acknowledgements}

The authors acknowledge funding from the National Key R\&D Program of China (2019YFD1002403), National Science Fund for Key Program of National Natural Science Foundation of China (31930084), Distinguished Young Scholars of China (31725022), China Agriculture Research System (CARS-18-ZJ0503), 
Science and Technology Planning Project of Guangdong Province (2019A050503002), Innovation and Entrepreneurship Team of Nanhai Talent Plan of Lanhai District, Foshan (201811070001).

\section{References}

Bavaro, T., Benucci, I., Pedrali, A., Marrubini, G., Esti, M., Terreni, M., Massolini, G., \& Ubiali, D. (2020). Lipase-mediated hydrolysis of hempseed oil in a packed-bed reactor and in-line purification of PUFA as mono- and diacylglycerols. Food and Bioproducts Processing, 123, 345-353. http://dx.doi.org/10.1016/j.fbp.2020.07.009.

Dalla Rosa, C., Morandim, M. B., Ninow, J. L., Oliveira, D., Treichel, H., \& Oliveira, J. V. (2009). Continuous lipase-catalyzed production of fatty acid ethyl esters from soybean oil in compressed fluids. Bioresource Technology, 100(23), 5818-5826. http://dx.doi.org/10.1016/j. biortech.2009.06.081. PMid:19616937.

Hu, B., Li, C., Zhang, Z., Zhao, Q., Zhu, Y., Su, Z., \& Chen, Y. (2017). Microwave-assisted extraction of silkworm pupal oil and evaluation of its fatty acid composition, physicochemical properties and antioxidant activities. Food Chemistry, 231, 348-355. http://dx.doi. org/10.1016/j.foodchem.2017.03.152. PMid:28450017.

Krüger, R. L., Valério, A., Balen, M., Ninow, J. L., Vladimir Oliveira, J., de Oliveira, D., \& Corazza, M. L. (2010). Improvement of mono and diacylglycerol production via enzymatic glycerolysis in tert-butanol system. European Journal of Lipid Science and Technology, 112(8), 921-927. http://dx.doi.org/10.1002/ejlt.200900253.

Li, D., Qin, X., Wang, J., Yang, B., Wang, W., Huang, W., \& Wang, Y. (2015). Hydrolysis of soybean oil to produce diacylglycerol by a lipase from Rhizopus oryzae. Journal of Molecular Catalysis. B, Enzymatic, 115, 43-50. http://dx.doi.org/10.1016/j.molcatb.2015.01.009.

Li, X., Li, D., Wang, W., Durrani, R., Yang, B., \& Wang, Y. (2016). Immobilization of SMG1-F278N lipase onto a novel epoxy resin: characterization and its application in synthesis of partial glycerides. Journal of Molecular Catalysis B: Enzymatic, 133, 154-160. http:// dx.doi.org/10.1016/j.molcatb.2016.08.011.

Li, Y., Zhong, N., Cheong, L.-Z., Huang, J., Chen, H., \& Lin, S. (2018). Immobilization of Candida antarctica Lipase B onto organicallymodified SBA-15 for efficient production of soybean-based mono and diacylglycerols. International Journal of Biological Macromolecules, 120(Pt A), 886-895. http://dx.doi.org/10.1016/j.ijbiomac.2018.08.155. PMid:30172818.

Qin, X. L., Wang, Y. M., Wang, Y. H., Huang, H. H., \& Yang, B. (2011). Preparation and characterization of 1,3-Dioleoyl-2-palmitoylglycerol.
Journal of Agricultural and Food Chemistry, 59(10), 5714-5719. http://dx.doi.org/10.1021/jf200398f. PMid:21510711.

Rodrigues, R. C., Ortiz, C., Berenguer-Murcia, Á., Torres, R., \& Fernández-Lafuente, R., (2013). Modifying enzyme activity and selectivity by immobilization. Chemical Society Reviews, 42(15), 6290-6307. http://dx.doi.org/10.1039/C2CS35231A. PMid:23059445.

Singh, A. K., \& Mukhopadhyay, M. (2014). Immobilization of Candida antarctica lipase onto cellulose acetate-coated $\mathrm{Fe} 2 \mathrm{O} 3$ nanoparticles for glycerolysis of olive oil. Korean Journal of Chemical Engineering, 31(7), 1225-1232. http://dx.doi.org/10.1007/s11814-014-0020-8.

Valério, A., Fiametti, K. G., Rovani, S., Franceschi, E., Corazza, M. L., Treichel, H., de Oliveira, D., \& Oliveira, J. V. (2009). Enzymatic production of mono- and diglycerides in compressed n-butane and AOT surfactant. The Journal of Supercritical Fluids, 49(2), 216-220. http://dx.doi.org/10.1016/j.supflu.2009.02.001.

Valério, A., Rovani, S., Treichel, H., de Oliveira, D., \& Oliveira, J. V. (2010). Optimization of mono and diacylglycerols production from enzymatic glycerolysis in solvent-free systems. Bioprocess and Biosystems Engineering, 33(7), 805-812. http://dx.doi.org/10.1007/ s00449-009-0402-1. PMid:20091052.

Wang, W., Li, T., Ning, Z., Wang, Y., Yang, B., \& Yang, X. (2011). Production of extremely pure diacylglycerol from soybean oil by lipase-catalyzed glycerolysis. Enzyme and Microbial Technology, 49(2), 192-196. http://dx.doi.org/10.1016/j.enzmictec.2011.05.001. PMid:22112408.

Wang, X., Li, D., Qu, M., Durrani, R., Yang, B., \& Wang, Y. (2017). Immobilized MAS1 lipase showed high esterification activity in the production of triacylglycerols with $\mathrm{n}-3$ polyunsaturated fatty acids. Food Chemistry, 216, 260-267. http://dx.doi.org/10.1016/j. foodchem.2016.08.041. PMid:27596418.

Wang, Y.-H., Mai, Q.-Y., Qin, X.-L., Yang, B., Wang, Z.-L., \& Chen, H.-T. (2010). Establishment of an evaluation model for human milk fat substitutes. Journal of Agricultural and Food Chemistry, 58(1), 642-649. http://dx.doi.org/10.1021/jf903048p. PMid:20000702.

Zeng, F., Yang, B., Wang, Y., Wang, W., Ning, Z., \& Li, L. (2010). Enzymatic production of monoacylglycerols with camellia oil by the glycerolysis reaction. Journal of the American Oil Chemists' Society, 87(5), 531-537. http://dx.doi.org/10.1007/s11746-009-1533-x.

Zha, B., Chen, Z., Wang, L., Wang, R., Chen, Z., \& Zheng, L. (2014). Production of glycerol monolaurate-enriched monoacylglycerols by lipase-catalyzed glycerolysis from coconut oil. European Journal of Lipid Science and Technology, 116(3), 328-335. http://dx.doi. org/10.1002/ejlt.201300243. 